\title{
LEVANTAMENTO DE BROMELIACEAE NA REGIÃO DO CURSO MÉDIO DO RIO TOROPI, RIO GRANDE DO SUL, BRASIL ${ }^{1}$
}

\author{
HENRIQUE MALLMANN BÜNEKER² LEOPOLDO WITECK-NETO³
}

\section{RESUMO}

Apresenta-se neste trabalho uma sinopse das espécies de Bromeliaceae da região do curso médio do rio Toropi (Rio Grande do Sul, Brasil), sendo também fornecida uma chave para identificação das espécies da região, fotografias e dados ecológicos das espécies e seus respectivos status de conservação quando existentes. $\mathrm{Na}$ área de estudo, Bromeliaceae encontra-se representada por 18 espécies e seis gêneros. Tillandsia e Dyckia foram os mais representativos.

Palavras-chave: Florística, bromélias, rio Toropi

\section{ABSTRACT}

[A floristic survey of Bromeliaceae in the middle course region of Toropi River, Rio Grande do Sul, Brazil].

In this paper is showed a floristic survey of the species of Bromeliaceae in the middle course of Toropi river, Rio Grande do Sul State (Brazil). It is also provided an identification key for the region species, photographs and ecological data of species and its respective status of conservation when available. In the study area, Bromeliaceae is represented by 18 species and six genera. Tillandsia and Dyckia were the most representative. Key words: Floristic, bromeliads, Toropi river

\section{INTRODUÇÃO}

Bromeliaceae é uma família essencialmente neotropical, composta por 58 gêneros e aproximadamente 3.199 espécies (Luther, 2012) de hábitos variados e, segundo análises filogenéticas baseadas em dados moleculares, é monofilética (Givnish et al., 2004, 2007, 2011). Atualmente, encontra-se representada por 44 gêneros e 1.323 espécies no Brasil, das quais 1.155 são endêmicas, ocorrendo em todos os ecossistemas desde o nível do mar até elevadas altitudes (Forzza et al., 2015).

No estado do Rio Grande do Sul, os primeiros levantamentos de espécies de Bromeliaceae foram organizados por Rambo (1967) e Reitz (1967), os quais citavam 43 e 47 espécies em 8 gêneros respectivamente. Estudos posteriores

1 Recebido em 04-04-2016 e aceito para publicação em $19 / 04 / 2016$.

2 Técnico em Paisagismo e acadêmico do curso de Engenharia Florestal, Universidade Federal de Santa Maria.henriquebuneker@mail.ufsm.br

3 Engenheiro Florestal, M.e. Professor do Colégio Politécnico da Universidade Federal de Santa Maria. 1witeck@gmail.com aumentaram o número de espécies gaúchas citando novas ocorrências ou descrevendo novas espécies (Büneker et al., 2013, 2014, 2015a, 2015b, 2015c; Ehlers, 1997; Irgang \& Sobral, 1987; Larocca \& Sobral, 2002; Leme \& Costa, 1991; Leme, 1995; Rauh, 1984; Smith, 1966, 1971, 1988, 1989; Strehl, 1997, 2000, 2004a, 2004b, 2008; Winkler, 1982). Dentre estes trabalhos destaca-se a ampla obra elaborada por Winkler (1982), constituída de chaves e descrições, consistindo no único tratamento taxonômico completo para as espécies de Bromeliaceae do Rio Grande do Sul, sendo citadas 69 espécies em 10 gêneros, entre estas foram descritas quatro novas espécies de Dyckia.

A compilação desta literatura resulta atualmente na citação de 120 espécies distribuídas em 10 gêneros para o Rio Grande do Sul, sendo que 34 espécies são endêmicas do estado (Forzza et al., 2015), sobressaindo-se em diversidade específica os gêneros Dyckia e Tillandsia.

No âmbito das flórulas regionais gaúchas poucos são os estudos específicos para Bromeliaceae, sendo que a maioria destes são levantamentos de epífitos vasculares (e.g. 
Perleberg \& Tomkowski, 2007; Waechter, 1986, 1992, 1998; Gonçalves \& Waechter, 2003; Rogalski \& Zanin, 2003; Gionco \& Waechter, 2004; Musskopf, 2002). Estes, no entanto, não abrangem todas espécies de bromélias das localidades, pois as espécies saxícolas, rupícolas ou terrícolas não são tratadas nestes levantamentos, gerando uma série de lacunas com relação a ocorrência destas espécies, principalmente as saxícolas e rupícolas que, notoriamente, apresentam alto grau de endemismo. Neste âmbito até o momento somente um estudo específico para Bromeliaceae existe para o estado, este apresenta uma chave para as espécies da área de estudo, sendo uma importante ferramenta para identificação dos táxons regionais (Strehl, 1998).

A região central do Rio Grande do Sul contém número relativamente elevado de espécies endêmicas, estas em geral muito pouco conhecidas pela comunidade científica. Sendo os refúgios desta flora endêmica ameaçados pelo crescente avanço da conversão das áreas em agricultura e os projetos de instalação de pequenas centrais hidrelétricas $(\mathrm{PCH})$ na região do curso médio do rio Toropi (Marchiori et al., 2014). Assim o presente trabalho traz a lume, vista a carência de literatura específica para Bromeliaceae em âmbito regional no Rio Grande do Sul, subsídio à identificação das espécies regionais, que inclui vários endemismos, tendo o objetivo de fornecer um levantamento de espécies, uma breve compilação de informações sobre suas distribuições e habitat, fotografias e uma chave para identificação.

\section{MATERIAL E MÉTODO}

A região do curso médio do Rio Toropi pertence a Região Hidrográfica do Uruguai, Bacia Hidrográfica do Rio Ibicuí e está contida em três municípios: São Martinho da Serra, Quevedos e Júlio de Castilhos. A vegetação da região é caracteristicamente ecótone, com áreas de campos e florestas. A região foi caracterizada florístico-fitogeograficamente por Marchiori et al. (2014).
Expedições para a região foram realizadas em diversas épocas do ano de 2011 a 2015. O levantamento das espécies foi feito através de caminhadas aleatórias nos três municípios que abrangem o curso médio do rio Toropi e a região final do rio Guassupi, próximo de sua afluência no rio Toropi. Foram verificados todos os nichos ecológicos onde comumente são encontradas espécies de Bromeliaceae: nas florestas, como epífitas e, nos campos, como terrícolas ou saxícolas, em afloramentos rochosos ou em escarpas rochosas (paredões). Espécimes testemunhos férteis foram fotografados e coletados ou, apenas fotografados e estão expostos nas páginas seguintes. Os espécimes coletados foram incorporados ao acervo do Herbário do Departamento de Ciências Florestais (HDCF).

As espécies foram identificadas através de literatura especializada: Rauh (1984), Smith \& Downs (1974, 1977, 1979), Strehl (1997, 1998), Winkler (1982). A chave foi elaborada através de dados contidos na literatura e de observação de espécimes vivos e herborizados. A terminologia morfológica segue Scharf \& Gouda (2008).

\section{RESULTADOS}

Foram encontradas 18 espécies de Bromeliaceae na região de estudo, pertencentes aos gêneros Aechmea (1 sp.), Billbergia (1 sp.), Bromelia (1 sp.), Dyckia (4 spp.), Tillandsia (9 spp.) e Vriesea (2 spp.). Destas, quatro são endêmicas do Rio Grande do Sul e duas da região central do estado. As espécies podem ser identificadas com a chave apresentada neste artigo e dados ecológicos podem ser observados na tabela 1 .

As espécies mais abundantes como epífitas ciófitas foram T. geminiflora e $V$. friburgensis; já como epífitas heliófitas, no dossel da mata ou em árvores isoladas, $T$. recurvata e $T$. stricta foram mais observadas. Aechmea recurvata e Billbergia nutans são pouco seletivas em relação a luminosidade e substrato, ocorrendo como epífitas ciófitas ou heliófitas, e também como saxícolas nas escarpas rochosas. Estas também encontradas eventualmente como rupícolas 
TABELA 1 - Espécies de bromeliáceas da região do curso médio do rio Toropi (Rio Grande do Sul): status de conservação e hábitat.

\begin{tabular}{|c|c|c|c|c|c|c|}
\hline \multirow{3}{*}{ Equeir } & \multirow{3}{*}{$\begin{array}{l}\text { Status de } \\
\text { eneaservarda } \\
\text { (RS', }^{2}, B^{2} \text { ) }\end{array}$} & \multicolumn{5}{|c|}{ Halbitai } \\
\hline & & \multirow{2}{*}{ Terricula } & \multicolumn{2}{|c|}{ Sasicela } & \multicolumn{2}{|c|}{ Epinta } \\
\hline & & & Aflaramentos & Fsearpas & Metisfita & Cosfita \\
\hline 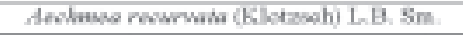 & LC, - & & & $\mathrm{x}$ & $\mathrm{x}$ & $\mathrm{x}$ \\
\hline Builergia mans H. Wenll ex flepel & $\mathrm{LC}, \mathrm{LC}$ & & & $\mathrm{x}$ & $x$ & $x$ \\
\hline Bremenas anfiacanflisa Bertol. & LC, - & $\mathrm{x}$ & & & & \\
\hline Dyckia ibismienvis StrehP & $\mathrm{CF}, \mathrm{CR}$ & $x$ & $\mathrm{x}$ & & & \\
\hline 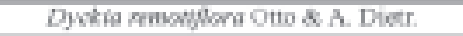 & $\mathrm{VU}, \mathrm{BN}$ & $\mathrm{x}$ & $x$ & & & \\
\hline Dyskia selioo (KK. Kooh) Baker? & $\mathrm{DD},=$ & $\bar{x}$ & $\bar{x}$ & $\mathbf{x}$ & & \\
\hline Dyskia strohilans H. Boneker \& R. Pontes & $\mathrm{CR}_{\text {, - }}$ & $\mathrm{x}$ & $\mathrm{x}$ & & & \\
\hline TWlandicin aerasthas (Loisel ) L. B. Sn & LC, LC & & & & $\mathrm{x}$ & $\mathrm{x}$ \\
\hline 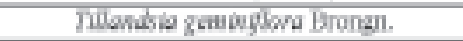 & $\mathrm{IK}_{S}, \mathrm{LC}$ & & & & $\mathrm{x}$ & $\mathrm{x}$ \\
\hline 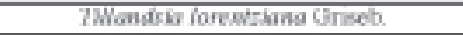 & $\mathrm{LC}, \mathrm{LC}$ & & & $\mathrm{x}$ & & \\
\hline 7 Wandix polrians Dex. & 4 & & & & $\mathrm{x}$ & \\
\hline Tüandsia mavrouria (1.) L. & $\mathrm{LC}_{\mathrm{i}}-$ & & & & $x$ & \\
\hline TNlonisis striste Sol. & $\mathrm{LC}_{\mathrm{i}}-$ & & & & $x$ & $\mathrm{x}$ \\
\hline 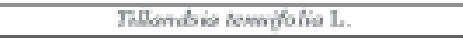 & LC, LC & & & & $\mathrm{x}$ & $x$ \\
\hline TWondes noregiensis Raief? & $\mathrm{CR}, \mathrm{DD}$ & & & $\mathbf{x}$ & & \\
\hline Jilondiu useneder (L.) I. & LC, L.C & & & & $\mathbf{x}$ & \\
\hline 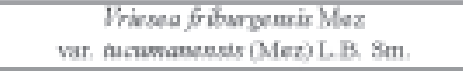 & $1 K, L C$ & & & & $\mathrm{x}$ & $\mathbf{x}$ \\
\hline 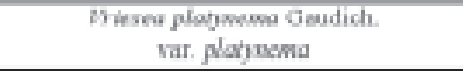 & LC, LC & & & & & $\mathrm{s}$ \\
\hline
\end{tabular}

${ }^{1}$ Rio Grande do Sul, 2014; ${ }^{2}$ Forzza et al., 2013; ${ }^{3}$ Espécie endêmica do Rio Grande do Sul.

heliófitas (diretamente sobre rochas), ou terrícolas ciófitas em substrato orgânico bem drenado no interior das matas de encostas.

Com ampla ocorrência na floresta ombrófila da costa do Brasil, V. platynema tem como seu limite meridional de distribuição o estado do Rio Grande do Sul. Neste estado é frequentemente encontrada na região serrana do nordeste. Sua ocorrência na região estudada possui relevante caráter fitogeográfico, visto que se trata do seu registro mais continental no Rio Grande do Sul. Esta espécie provavelmente tenha no passado migrado da região litorânea até o interior do continente pelas florestas ocorrentes no rebordo do planalto meridional. Entretanto verificou-se uma grande lacuna de amostragem entre as populações intermediárias que ligariam estas regiões.
Aparentemente, a espécie mais rara na região, revelou-se T. pohliana, sendo observados apenas dois espécimes no dossel da mata ciliar. Esta espécie até pouco tempo não era citada para o Rio Grande do Sul (Büneker et al., 2015c). A sua ocorrência neste ambiente é incomum, pois é epífita associada, geralmente, à formações vegetacionais abertas, como em capões de mata nas bases de cornijas e cerros, na região oeste do Rio Grande do Sul, e no cerrado e caatinga nas demais regiões do Brasil.

Endêmica da região central do Rio Grande do Sul, T. toropiensis mostra-se abundante como saxícola ou rupícola nas numerosas escarpas rochosas da localidade, crescendo juntamente com grandes populações de $D$. selloa. O epíteto da primeira, inclusive, faz referência ao rio Toropi, pois foram originários de uma destas 
escarpas rochosas às margens do rio Toropi os espécimes que deram origem à coleção tipo da espécie e a maioria das plantas vivas descendentes desta coleta que encontram-se distribuídas pelo mundo em coleções vivas. Esta espécie foi coletada na década de 70 por Werner Rauh (19132000), ilustre botânico alemão, especialista em taxonomia de Bromeliaceae, que na ocasião excursionava pelo sul do Brasil (Rauh, 1984).

Criticamente ameaçada (Rio Grande do Sul, 2014) e recentemente descrita, a reófita $D$. strehliana mostra-se muito peculiar, visto que ocorre exclusivamente sobre afloramentos rochosos nas margens do rio Toropi, sendo submetida a inundações frequentes (Büneker et al., 2013). Mostrando-se sua conservação uma das principais preocupações vistos os represamentos previstos para a implantação de pequenas centrais hidrelétricas na região (Marchiori et al., 2014), assim como D. distachya Hassler, na bacia do alto Uruguai (na divisa do Rio Grande do Sul e Santa Catarina), que gerou uma série de discussões entre ambientalistas e órgãos governamentais (Prochnow, 2005; Wiesbauer, 2008; Wiesbauer et al., 2009). Menos rara na região, porém também considerada criticamente ameaçada pelo Livro Vermelho da Flora do Brasil (Forzza et al., 2013), D. ibicuiensis apresenta-se em diversas populações no região, ocorrendo como saxícola em afloramentos rochosos ou terrícola em solo litólico de escarpas de declividade moderada.

Dyckia remotiflora é rara na região, sendo encontrada como terrícola em campos com solo litólico, em cotas mais elevadas e afastadas do leito do rio, consequentemente. Durante o período de estudo, seu habitat foi drasticamente alterado, pois os campos com vegetação natural, ocupados pela pecuária, foram convertidos em lavouras de grãos e campos plantados com gramíneas sazonais. Com isso provavelmente a espécie deixará de existir na região em curto período de tempo.

Muito frequentes na região central e com potencial de ocorrência na região de estudo são: Billbergia zebrina (Herb.) Lindl., $T$. streptocarpa Baker e T. tricholepis Baker. Estas espécies possivelmente ocorrem na região e levantamentos posteriores na localidade podem confirmar suas ocorrências.

\section{Chave para identificação de espécies de Bromeliaceae ocorrentes na região do curso médio do rio Toropi}

1a. Folhas com espinho no ápice ou com margens espinhoso-serradas ................................ 2

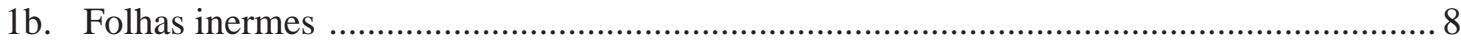

2a. Fruto carnoso, indeiscente, do tipo baga; ovário ínfero ................................................ 3

2b. Fruto seco, deiscente, do tipo cápsula; ovário semi-ínfero ou súpero ............................5

3a. Inflorescência composta; flores com pétalas branco-azuladas; frutos amarelos, lisos; planta terrícola Bromelia antiacantha (Fig. 1 C-D)

3b. Inflorescência simples; flores com pétalas verde-azuladas, amarelo-azuladas ou róseas; frutos rosados, esverdeados ou preto-arroxeados, estriados; planta epífita ou saxícola ..... 4

4a. Inflorescência congesta, pedúnculo inconspícuo; brácteas florais avermelhadas; pétalas róseas a lilases, com ápice arredondado-cuculado Aechmea recurvata (Fig. $1 \mathrm{~A})$

4b. Inflorescência laxa, pedúnculo conspícuo; brácteas florais róseas; pétalas amareladas ou esverdeadas, com margens azuis, ápice agudo Billbergia nutans (Fig. 1 B)

5a. Inflorescência composta, amplamente paniculada com mais de 15 ramos; eixo da inflorescência, ramos e sépalas glabros ou pruinosos; pétalas não distintamente segmentadas em unha e lâmina, oblongas; sementes ovoides ...... Dyckia selloa (Fig. 2 A) 
5b. Inflorescência simples ou composta com até 4 ramos; eixo da inflorescência, ramos e sépalas tomentosos; pétalas distintamente segmentadas em unha e lâmina, obtrulado-romboides; sementes triangular-discoides . . .

6a. Planta estolonífera; pétalas alaranjadas Dyckia remotiflora (Fig. 2 D)

6b. Planta rizomatosa; pétalas amareladas 7

7a. Brácteas florais da base do eixo principal da inflorescência ultrapassando o comprimento das flores; pedicelos conspícuos, 0,6-0,7 cm compr.; filetes conatos a cima do tubo comum com as pétalas .................. Dyckia ibicuiensis (Fig. 2 B-C)

7b. Brácteas florais da base do eixo principal da inflorescência não ultrapassando o comprimento das flores; pedicelos inconspícuos ca. 0,1 cm compr.; filetes livres acima do tubo comum com as pétalas Dyckia strehliana (Fig. 3 A-C)

8a. Flores com pétalas amarelas, providas de apêndices petalíneos na base da face adaxial

8b. Flores com pétalas de outras cores, desprovidas de apêndices petalíneos na base da face adaxial

9a. Folhas adaxialmente vernicosas com ápice revoluto-agudo; inflorescência composta; brácteas florais amareladas Vriesea friburgensis var. tucumanensis (Fig. 6 B)

9b. Folhas adaxialmente pruinosas com ápice arredondado-apiculado; inflorescência simples; brácteas florais avermelhadas ........ Vriesea platynema var. platynema (Fig. 6 C)

10a. Caule alongado conspícuo, folhas laxamente dispostas; pétalas esverdeadas Tillandsia usneoides (Fig. 6 A)

10b. Caule pouco alongado inconspícuo, folhas densamente dispostas; pétalas brancas, azuladas ou rosadas

11a. Folhas dísticas; inflorescência 1-3 flora Tillandsia recurvata

11b. Folhas polísticas; inflorescência com mais de 5 flores 12

12a. Flores dísticas 13

12b. Flores polísticas. 14

13a. Inflorescência congesta; pétalas róseas

13b. Inflorescência laxa; pétalas brancas Tillandsia geminiflora (Fig. 4 A, C)

14a. Brácteas florais róseas Tillandsia lorentziana

14b. Brácteas florais avermelhadas, esverdeadas ou alaranjadas

15a. Brácteas florais infladas; sépalas igualmente conatas pela base; cápsulas longo-cilíndricas Tillandsia stricta (Fig. 5 A-B)

15b. Brácteas florais adpressas às flores; sépalas adaxiais amplamente conatas e a abaxial livre; cápsulas curto-elipsóidicas

16a. Folhas estreitas, sublineares, amplamente atenuadas, eretas; pétalas azuis-claro Tillandsia tenuifolia (Fig. 5 C)

16b. Folhas estreito-triangulares, agudas, subereto-patentes; pétalas azuis-escuro Tillandsia aeranthos (Fig. 3 D)

17a. Planta epífita; brácteas florais infladas, alaranjadas ou esverdeadas; sépalas igualmente conatas pela base; cápsulas longo-cilíndricas Tillandsia pohliana (Fig. 4 B, D)

17b. Planta saxícola; brácteas florais adpressas as flores, avermelhadas; sépalas adaxiais amplamente conatas e a abaxial livre; cápsulas curto-elipsóidicas Tillandsia toropiensis (Fig. 5 D-E) 


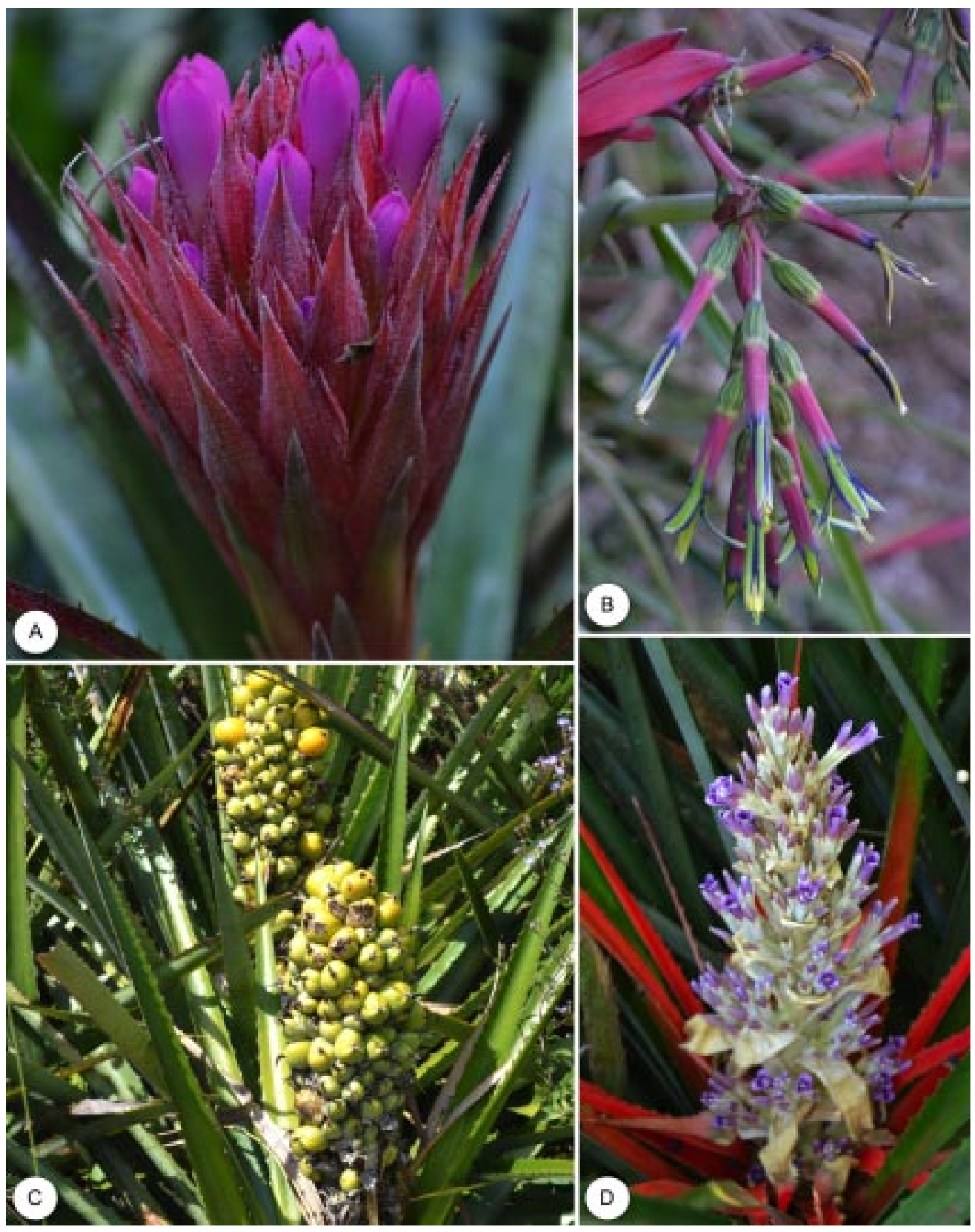

FIGURA 1 - A - Detalhe da inflorescência de Aechmea recurvata. B - Detalhe da inflorescência de Billbergia nutans. C - Detalhe da infrutescência de Bromelia antiacantha. D - Detalhe da inflorescência de Bromelia antiacantha. 

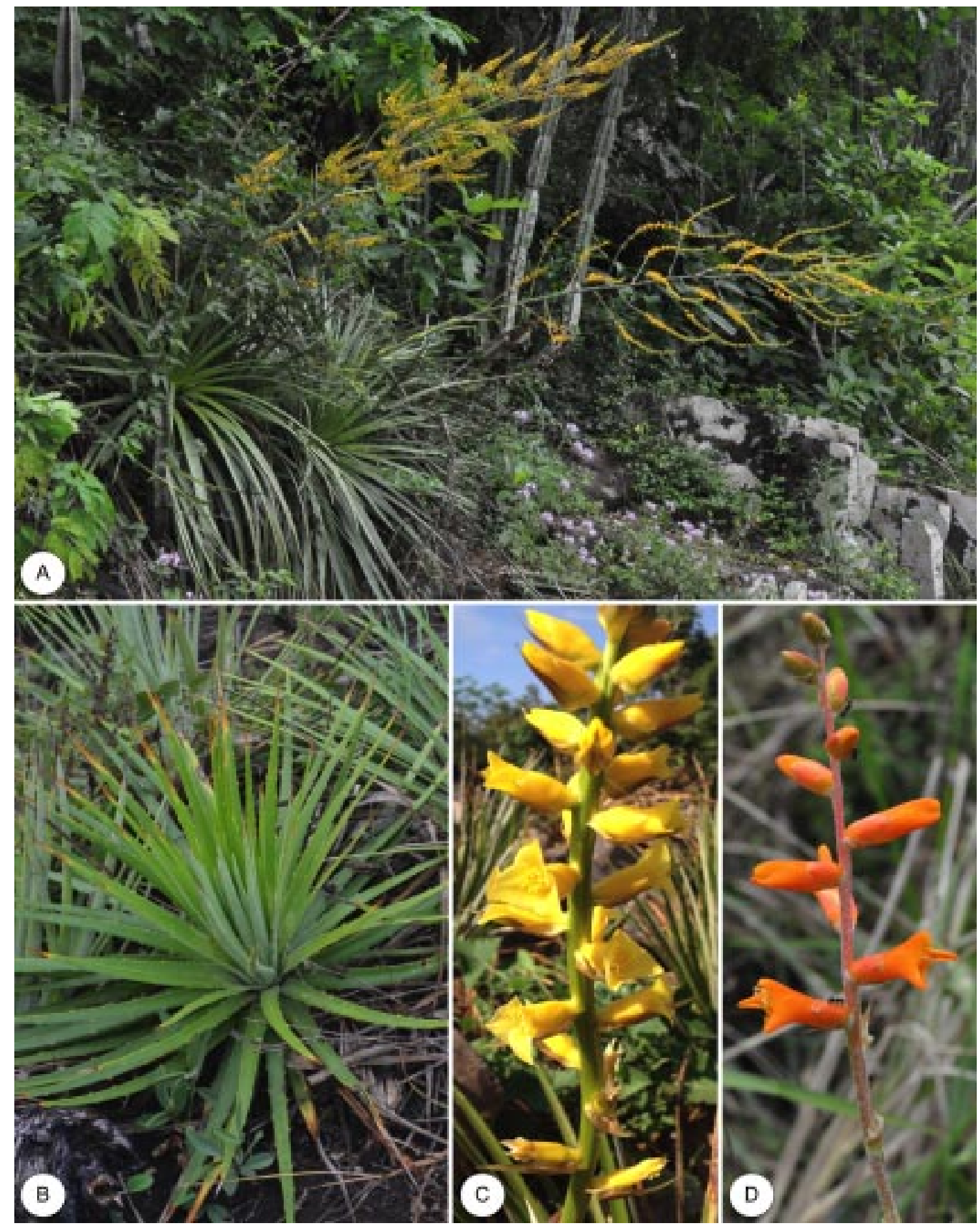

FIGURA 2 - A - Hábito de Dyckia selloa. B - Hábito vegetativo de Dyckia ibicuiensis. C - Detalhe da inflorescência de Dyckia ibicuiensis. D - Detalhe da inflorescência de Dyckia remotiflora. 


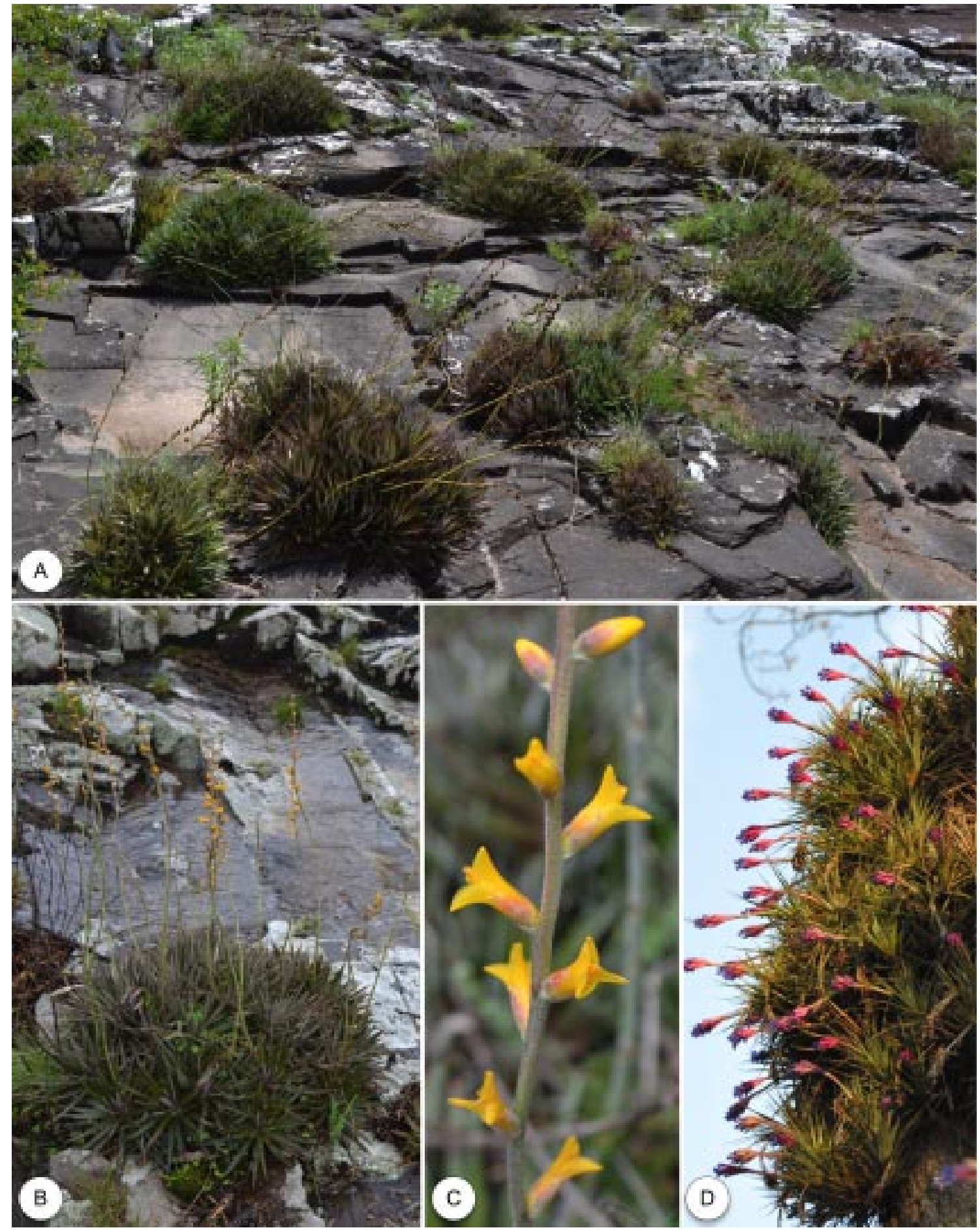

FIGURA 3 - A - Hábito e hábitat de Dyckia strehliana em afloramentos rochosos às margens do rio Toropi. B - Hábito de Dyckia strehliana. C - Detalhe da inflorescência de Dyckia strehliana. D - Hábito de Tillandsia aeranthos. 


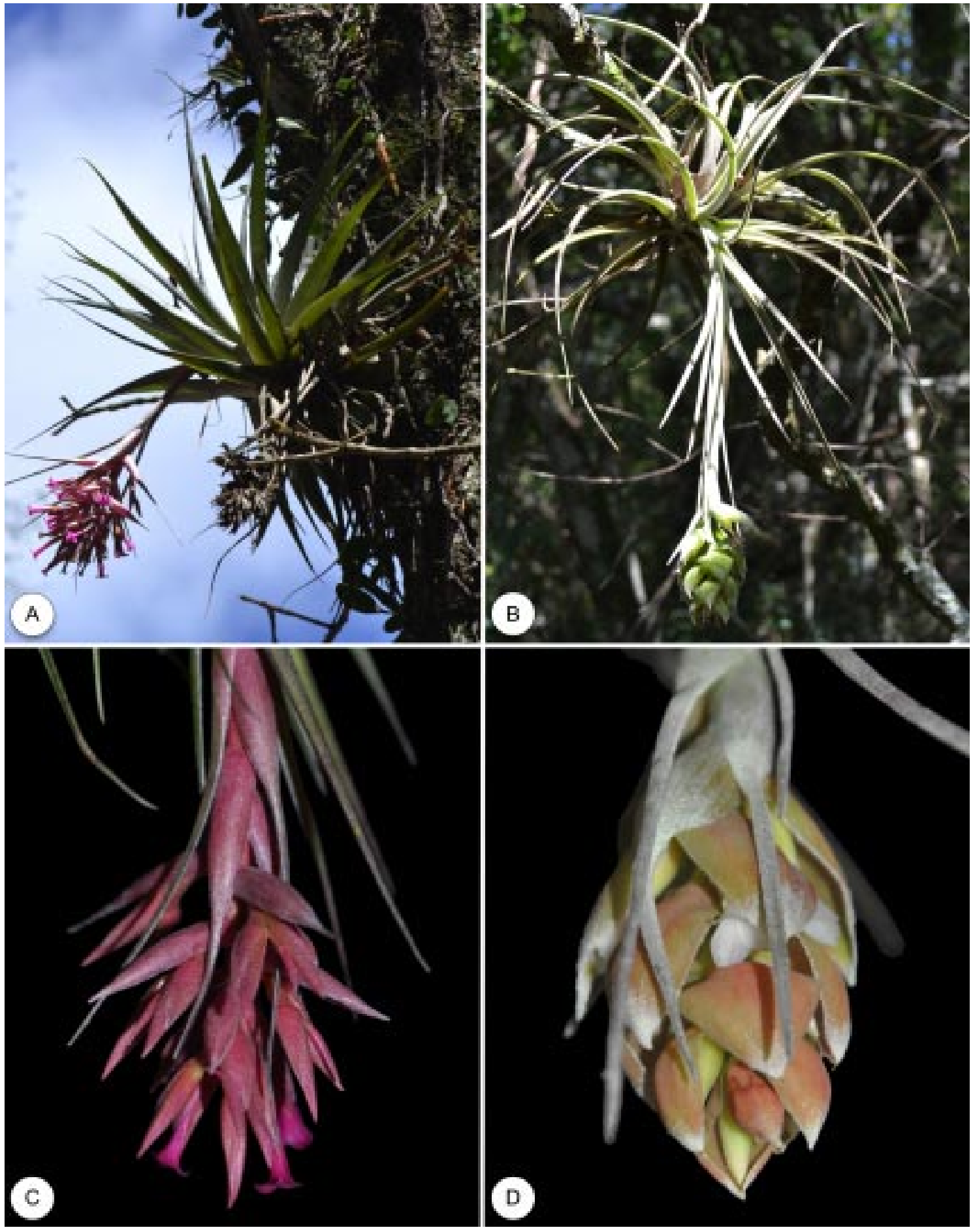

FIGURA 4 - A - Hábito de Tillandsia geminiflora. B - Hábito de Tillandsia pohliana. C - Detalhe da inflorescência de Tillandsia geminiflora. D - Detalhe da inflorescência de Tillandsia pohliana. 


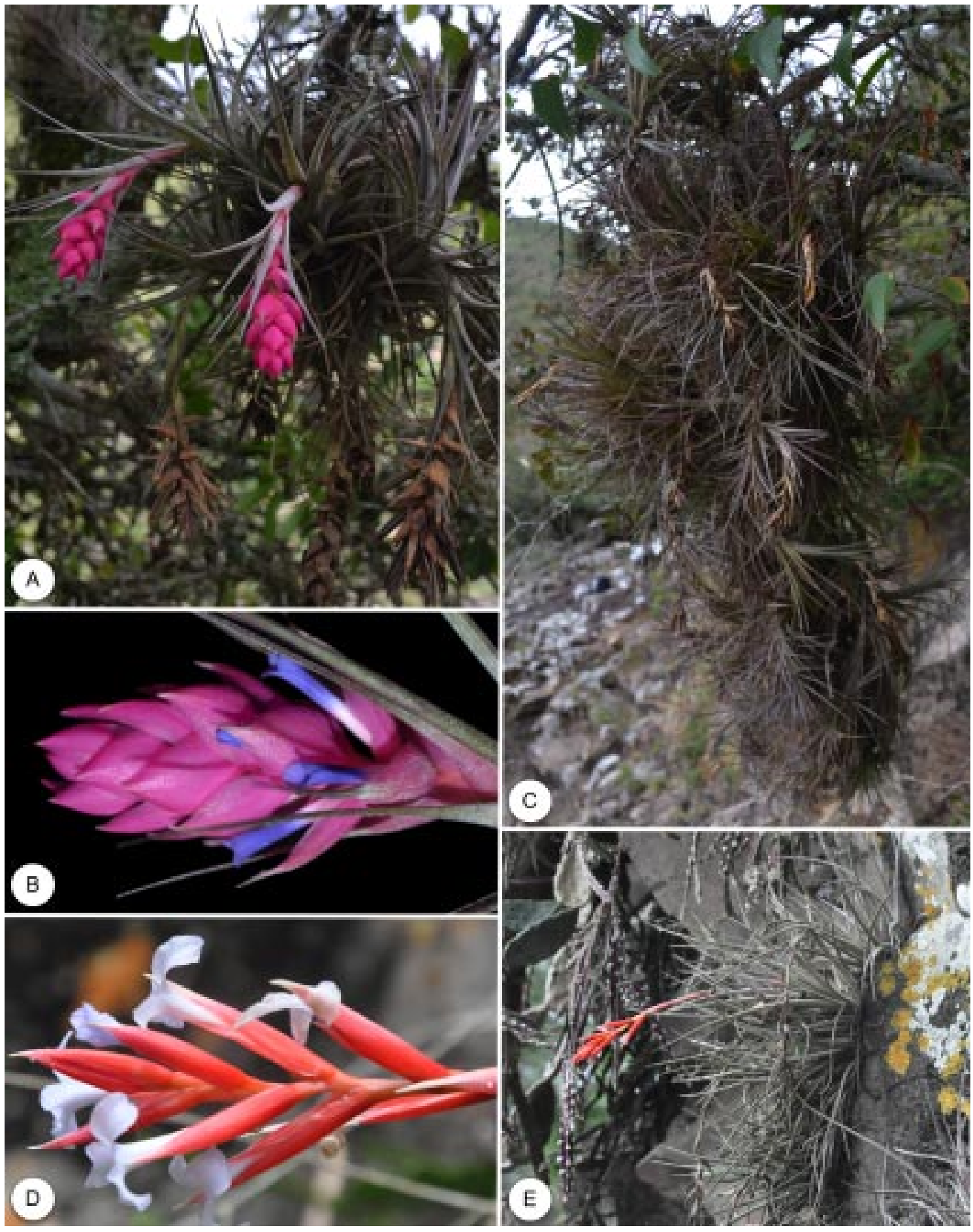

FIGURA 5 - A - Hábito de Tillandsia stricta. B - Detalhe da inflorescência de Tillandsia stricta. C - Hábito de Tillandsia tenuifolia. D - Detalhe da inflorescência de Tillandsia toropiensis. D - Hábito de Tillandsia toropiensis em escarpas rochosas às margens do rio Guassupi. 


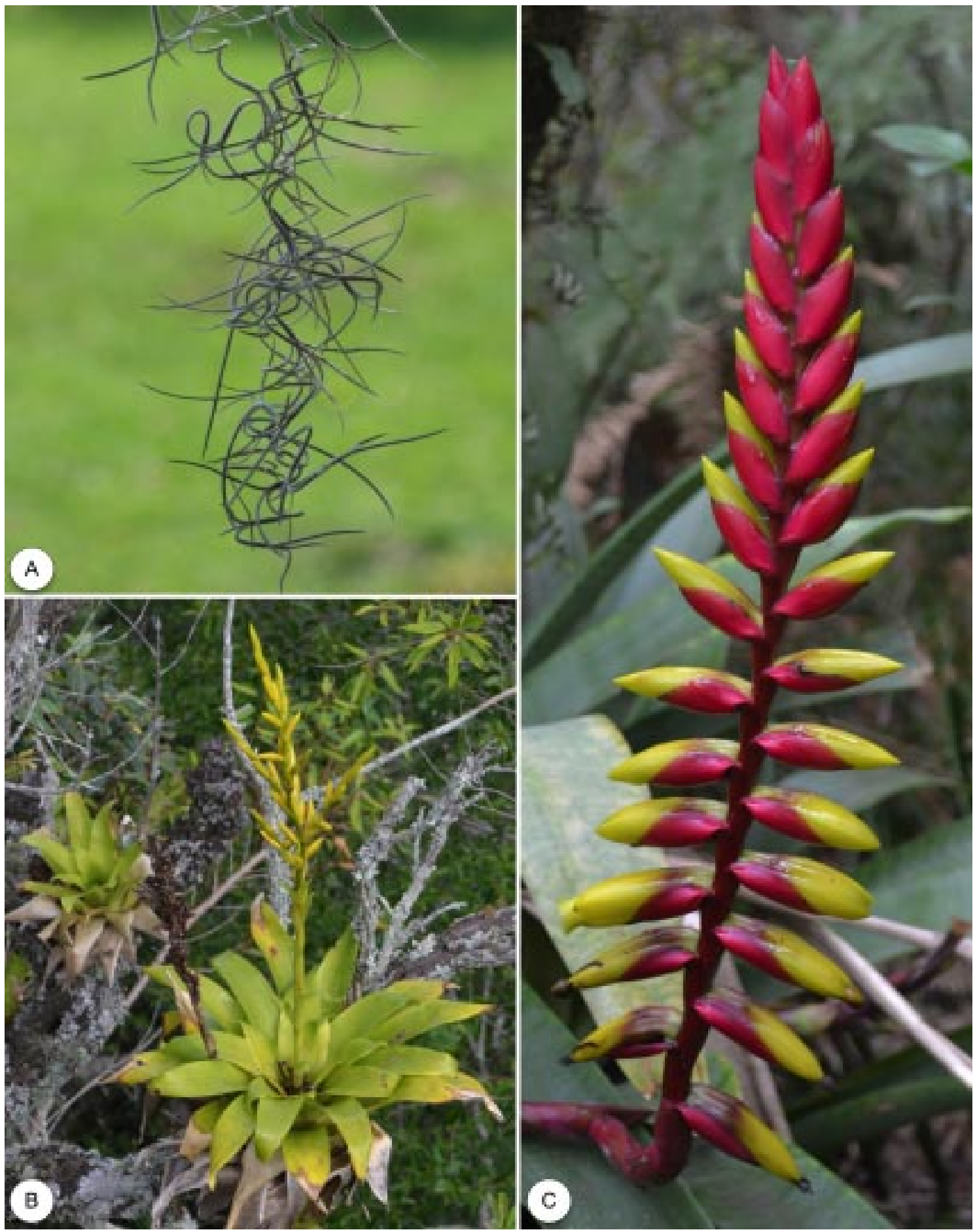

FIGURA 6 - A - Hábito vegetativo de Tillandsia usneoides. B - Hábito de Vriesea friburgensis var. tucumanensis. C - Detalhe da inflorescência de Vriesea platynema var. platynema. 
AGRADECIMENTOS

Ao Colégio Politécnico da Universidade Federal de Santa Maria pelo financiamento do projeto de pesquisa que aqui traz a lume os resultados. Aos proprietários das áreas onde foram realizados os levantamentos e a Rodrigo Corrêa Pontes pelo auxílio nas expedições a campo.

\section{REFERÊNCIAS BIBLIOGRÁFICAS}

BÜNEKER, H.M.; PONTES, R.C.; SOARES, K.P. Duas novas espécies de Tillandsia L., subgênero Anoplophytum (Beer) Baker (Bromeliaceae, Tillandsioideae) para a flora sul brasileira. Iheringia. Série Botânica, v. 69, p. 89-96, 2014. BÜNEKER, H.M.; PONTES, R.C.; SOARES, K.P.; WITECK-NETO, L.; LONGHI, S.J. Uma nova espécie reófita de Dyckia (Bromeliaceae, Pitcairnioideae) para a flora do Rio Grande do Sul, Brasil. Revista Brasileira de Biociências, v. 11, n. 3, p. 284-289, 2013.

BÜNEKER, H.M.; PONTES, R.C.; WITECK, L. Novos registros em Tillandsia L. (Bromeliaceae, Tillandsioideae) para o Rio Grande do Sul, Brasil. Rodriguésia, v. 66, n. 2, p. 493-498, 2015c.

BÜNEKER, H.M.; PONTES, R.C.; WITECK, L.; SOARES, K. P. Tillandsia leucopetala, a new species of Bromeliaceae from Rio Grande do Sul, southern Brazil. Phytotaxa, v. 202, p. 143148, 2015a.

BÜNEKER, H.M.; WITECK, L.; SOARES, K.P. Dyckia pontesii (Bromeliaceae, Pitcairnioideae), uma nova espécie do Rio Grande do Sul, Brasil. Rodriguésia, v. 66, p. 499-504, 2015 b.

EHLERS, R. Tillandsia polzii R. Ehlers spec. nov. Die Bromelie, v. 1997, p. 11-15, 1997.

FORZZA, R.C.; COSTA, A.; SIQUEIRA FILHO, J.A.; MARTINELLI, G.; MONTEIRO, R.F.; SANTOS-SILVA, F.; SARAIVA, D.P.; PAIXÃO-SOUZA, B.; LOUZADA, R.B.; VERSIEUX, L. Bromeliaceae. In: Lista de Espécies da Flora do Brasil. Jardim Botânico do Rio de Janeiro. 2015.

FORZZA, R.C.; COSTA, A.F. DA; LEME, E.M.C.; VERSIEUX, L. DE M.; WANDERLEY, M. DAS G.L.; LOUZADA, R.B.; MONTEIRO, R.F.; JUDICE, D.M.; FERNANDEZ, E.P.; BORGES, R.A.X.; PENEDO, T.S. DE A.;
MONTEIRO, N.P.; MORAES, M.A. Bromeliaceae. In: MARTINELLI, G.; MORAES, M.A. (Orgs.) Livro Vermelho da Flora do Brasil. Andrea Jakobsson, Rio de Janeiro, p. 1-1100, 2013.

GIONGO, C.; WAECHTER, J.L. Composição florística e estrutura comunitária de epífitos vasculares em uma floresta de galeria na Depressão Central do Rio Grande do Sul. Revista Brasileira de Botânica, v. 27, n. 3, p. 563-572, 2004.

GIVNISH, T.J.; BARFFUS, M.H.J.; VAN E.B.; RIINA, R.; SCHULTE, K.; HORRES, R.; GONSISKA, P.A.; JABAILY, R.S.; CRAYN, D.M.; SMITH, J.A.C.; INVERNO, K.; BROWN, G.K.; EVANS, T.M.; HOLST, B.K.; LUTHER, H.; TILL, W.; ZIZKA, G.; BARRY, P.E.; SYTSMA K.J. Phylogeny, adaptative radiation, and historical biogeography in Bromeliaceae: insights from an eight-locus plastid phylogeny. American Journal of Botany, v. 98, p. 872-895, 2011.

GIVNISH, T.J.; MILLAM, K.C.; EVANS, T. M; HALL, J.C.; PIRES, J.C.; BERRY P.E.; SYTSMA, K.J. Ancient vicariance or recent long-distance dispersal? Inferences about phylogeny and South American - African disjunction in Rapateaceae and Bromeliaceae based on $\mathrm{ndhF}$ sequence data. International Journal of Plant Sciences, v. 165, p. 35-54, 2004.

GIVNISH, T.J.; MILLAN, K.C.; BERRY, P.E.; SYTSMA K.J. Phylogeny, adaptive radiation, and historical biogeography of Bromeliaceae inferred from ndhF sequence data. In: COLUMBUS, J.T.; FRIAR, E.A.; PORTER, J.M.; PRINCE, L.M.; SIMPSON, M.G. Monocots: Comparative biology and evolution - Poales, Rancho Santa Ana Botanic Garden, Claremont, 2007. p. 3-26.

GONÇALVES, C.N.; WAECHTER, J.L. Aspectos florísticos e ecológicos de epífitos vasculares sobre figueiras isoladas no norte da planície costeira do Rio Grande do Sul. Acta Botanica Brasilica, v. 17, p. 89-100, 2003.

IRGANG, B.E.; SOBRAL, M. Dyckia agudensis (Bromeliaceae), nova espécie do Rio Grande do Sul, Brasil. Napaea, v. 3, p. 5-7, 1987.

LAROCCA, J.; SOBRAL, M. Dyckia delicata (Bromeliaceae), a new species from Rio Grande do Sul, Brazil. Novon, v. 12, p. 234-236, 2002. 
LEME, E.M.C. Novas Bromeliáceas Nativas do Brasil - XIII. Pabstia, v. 6, p. 1-6, 1995.

LEME, E.M.C.; COSTA, A. A New Vriesea Species from Southern Brazil; A Tribute to Father Raulino Reitz. Journal of the Bromeliad Society, v. 41, p. 195-198, 1991.

LUTHER, H.E. An alphabetical list of bromeliad binomials. Marie Selby Botanical Gardens and Bromeliad Society International, Sarasota, 2012. $44 \mathrm{p}$.

MARCHIORI, J.N.C.; CANTO-DOROW, T.S. DO; BÜNEKER, H.M.; ESSI, L.; BREIER, T.B.; PONTES, R.C. Campos e florestas no curso médio do Rio Toropi, Rio Grande do Sul (Brasil). Retrato de um admirável patrimônio ameaçado. Balduinia, v. 45, p. 1-16, 2014.

MUSSKOPF, M.L. Composição e distribuição ecológica de epífitos vasculares do Parque Estadual de Itapuã, Viamão, Rio Grande do Sul. Dissertação de Mestrado. Universidade Federal do Rio Grande do Sul, Porto Alegre. 2002. 58 p.

PERLEBERG, T.D.; TOMKOWSKI, P.B.P. Bromeliaceae e Orchidaceae Epífitas nas Trilhas do Ecocamping Municipal de Pelotas, RS, Brasil. Revista Brasileira de Biociências, Porto Alegre, v. 5, n. 2, p. 720-722, 2007.

PROCHNOW, M. A importância das florestas do vale do rio Pelotas. In: PROCHNOW, M. (Org.). Barra Grande: a hidrelétrica que não viu a floresta. Rio Grande do Sul: Apremavi, 2005. p. 8-14.

RAMBO, B. Bromeliaceae Riograndenses. Pesquisas, Série Botânica, v. 25, p. 1-27, 1967.

RAUH, W. Bromelienstudien, Tillandsia toropiensis. Tropische und Subtropische Planzenwlt, v. 50, p. 10-13, 1984.

REITZ, R. Lista das Bromeliáceas da região sul. Sellowia. Anais botânicos do Herbário Barbosa Rodrigues, v. 19, p. 101-107, 1967.

RIO GRANDE DO SUL. Diário oficial, decreto ${ }^{\circ}$. 52.109, 2014.

ROGALSKI, J.M.; ZANIN, E.M. Composição florística de epífitos vasculares no estreito de Augusto César, Floresta Estacional Decidual do Rio Uruguai, RS, Brasil. Revista Brasileira de Botânica, v. 26, p. 551-556, 2003.

SCHARF, U.; GOUDA, E.J. Bringing Bromeliaceae back to homeland Botany. Journal of the Bromeliad Society, v. 58, n. 1, p. 123-129, 2008.
SMITH, L.B. A giant Dyckia mystery. Journal of the Bromeliad Society, v. 38, p. 248-249, 1988.

MITH, L.B. Another giant Dyckia mystery. Journal of the Bromeliad Society, v. 39, p. 206-207, 1989.

SMITH, L.B. Notes on Bromeliaceae, XXIII. Phytologia, v. 13, p. 84-161, 1966.

SMITH, L.B. Notes on Bromeliaceae, XXXII. Phytologia, v. 21, p. 73-96, 1971.

SMITH, L.B.; DOWNS, R.J. Bromeliaceae (Bromelioideae). Flora Neotropica Monograph, v. 14, n. 3, p. 1493-2142, 1979.

SMITH, L.B.; DOWNS, R.J. Bromeliaceae (Pitcairnioideae). Flora Neotropica Monograph, v. 14, n. 1, p. 1-662, 1974.

SMITH, L.B.; DOWNS, R.J. Bromeliaceae (Tillandsioideae). Flora Neotropica Monograph, v. 14, n. 2, p. 663-1492, 1977.

STREHL, T. Contribuição ao conhecimento da diversidade de Bromeliaceae no Rio Grande do Sul, Brasil. Divulgações do Museu de Ciências e Tecnologia da UBEA/PUCRS, Porto Alegre, v. 9, p. 25-32, 2004a.

STREHL, T. Flora Fanerogâmica da Reserva Biológica do Ibicui Mirim, Santa Maria, Rio Grande do Sul. Bromeliaceae. Iheringia. Série Botânica, Porto Alegre, v. 51, n.1, p. 17-37, 1998.

STREHL, T. New bromeliads, genus Dyckia, from Rio Grande do Sul, Brazil. Bromeliaceae, v. 42, p. 8-22, 2008.

STREHL, T. Novas bromélias da flora gaúcha I, Dyckia ibicuiensis Strehl sp. nov. Bromélia, v. 4, p.14-16, 1997.

STREHL, T. Novas espécies de Bromeliaceae do Rio Grande do Sul, Brasil. Vidalia, v. 2, p. 19-25, 2004b.

STREHL, T. Novos táxons de Tillandsia subgênero Anoplophytum (Bromeliaceae) do Rio Grande do Sul, Brasil. Iheringia. Série Botânica, v. 54, p. 19-44, 2000.

WAECHTER, J.L. Epifitismo vascular em uma floresta de restinga do Brasil subtropical. Ciência e Natura, Santa Maria, v. 20, p. 43-66, 1998.

WAECHTER, J.L. Epífitos vasculares da mata paludosa do Faxinal, Torres, Rio Grande do Sul, Brasil. Iheringia, Série Botânica, Porto Alegre, v. 34, p. 39-49, 1986.

WAECHTER, J.L. O epifitismo vascular na planície costeira do Rio Grande do Sul. Tese de Doutorado, Curso de Pós- Graduação em Ecologia e 
Recursos Naturais, Universidade Federal de São Carlos, São Carlos. 1992. 163 p.

WIESBAUEER, M.B. Biologia reprodutiva e diversidade genética de Dyckia distachya Hassler (Bromeliaceae) como subsídio para a conservação e reintrodução de populações extintas na natureza. Dissertação de Mestrado, Universidade Federal de Santa Catarina, Florianópolis, 2008. 95 p.
WIESBAUER, M.B.; HMELJEVSKI, K.V.; ZIMMERMANN, T.G.; REIS, M.S. dos; REIS, A.; SOUZA, S. L. de. Reintrodução de Dyckia distachya Hassler nas áreas de influência das hidrelétricas de Itá e Machadinho. Universidade Federal de Santa Catarina, Florianópolis, 2009. 23 p.

WINKLER, S. Die Bromeliaceae von Rio Grande do Sul, Südbrasilien. Documenta Naturae, v. 3, p. 1-90, 1982. 